\title{
Erratum to "Analysis of Efficiencies for Multiple-Input Multiple-Output Wireless Power Transfer Systems"
}

\author{
Sejin Kim · Bomson Lee*
}

In the paper entitled "Analysis of Efficiencies for Multiple-Input Multiple-Output Wireless Power Transfer Systems (Journal of Electromagnetic Engineering and Science, vol. 16, no. 2, pp. 126-133, 2016)", we accidentally inserted the wrong list of references by mistake. The full list of references has now been revised as follows.

\section{REFERENCES}

[1] R. Tseng, B. von Novak, S. Shevde, and K. A. Grajski, "Introduction to the alliance for wireless power loosely-coupled wireless power transfer system specification version 1.0," in Proceedings of IEEE Wireless Power Transfer, Perugia, Italy, 2013, pp. 79-83.

[2] H. Shoki, "Trends, technical and regulatory issues, and standardization concerning commercialization of wireless power transfer technologies," in Proceedings of IEEE Asia-Pacific Microwave Conference, Sendai, Japan, 2014, pp. 1095-1097.

[3] H. D. Lang, A. Ludwig, and C. D. Sarris, "Optimization and design sensitivity of SISO and MISO wireless power transfer systems," in Proceedings of IEEE International Symposium on Antennas and Propagation Society, Vancouver, Canada, 2015, pp. 406-407.

[4] D. Ahn and S. Hong, "Effect of coupling between multiple transmitters or multiple receivers on wireless power transfer," IEEE Transactions on Industrial Electronics, vol. 60, no. 7, pp. 2602-2613, 2013.

[5] M. Q. Nguyen, Y. Chou, D. Plesa, S. Rao, and J. C. Chiao, "Multiple-inputs and multiple-outputs wireless power combining and delivering systems," IEEE Transactions on Power Electronics, vol. 30, no. 11, pp. 6254-6263, 2015.

[6] C. Kim and B. Lee, "Analysis of magnetically coupled wireless power transmission for maximum efficiency," Journal of Electromagnetic Engineering and Science, vol. 11, no. 3, pp. 156-160, 2011.

[7] G. Kim and B. Lee, "Analysis of magnetically coupled wireless power transfer between two resonators based on power conservation," in Proceedings of IEEE Wireless Power Transfer Conference, Jeju, Korea, 2014, pp. 231-234.

[8] S. Kang, V. T. Nguyen, and C. Jung, "Analysis of WPT system using rearranged indirect-fed method for mobile applications," in Proceedings of IEEE Wireless Power Transfer Conference, Boulder, CO, 2015, pp. 1-4.

[9] Y. Jung and B. Lee, "Design tunable optimal load circuit for maximum wireless power transfer efficiency," Microwave and Optical Technology Letters, vol. 56, no. 11, pp. 2619-2622, 2014.

[10] H. Park, M. Kwon, M. Kim, H. Park, and H. Ku, "Analysis and modeling of wireless power transfer systems using magnetically coupled resonator scheme with relay coils," Journal of the Korean Institute of Illuminating and Electrical Installation Engineers, vol. 28, no. 1, pp. 69-78, 2014.

[11] J. T. Conway, "Inductance calculations for noncoaxial coils using Bessel functions," IEEE Transactions on Magnetics, vol. 43, no. 3, pp. 1023-1034, 2007. 